\title{
Selecting Corn Agronomic Traits in Breeding high potential Yield: effects of Stem Structure
}

\author{
Yuan Huan-Huan ${ }^{1,2}$, Yang Gui-Jun ${ }^{2}$, Zhang Guang-Sheng ${ }^{1}$, Feng Hai-Kuan ${ }^{2, a}$, \\ Wang Yan-Jie ${ }^{1,2}$ \\ ${ }^{1}$ School of Surveying and Land Information Engineering, Henan Polytechnic University, Jiaozuo \\ 454003, China \\ ${ }^{2}$ National Engineering Research Center for Information Technology in Agriculture, Beijing 100097, \\ China
}

afenghaikuan123@163.com

Keywords: economic coefficient, agronomic traits, stem diameter, path analysis.

\begin{abstract}
To explore the effects of stem structure on biomass, yield and economic coefficient of corn, the grey relation analysis, correlation analysis and path analysis were used to analyze the relationship of 5 agronomic traits of corn (Jing Hua No. 8), which conducted in 2015 at National Precision Agriculture Research Station. The results show that, stem height has closely related with biomass, base stem diameter direct influence is 0.68 , which is the largest influence on yield, however, top stem diameter show great contribution to stem height and base stem diameter, moreover it expressing significant direct and indirect impact on biomass, economic coefficient, the value is $-0.52,0.385$, $0.67,0.348$, selecting the appropriate top stem diameter will help improving the potential yield of corn.
\end{abstract}

\section{Introduction}

Corn biomass, yield and economic coefficient were determined by multiple interaction factors, while the stem has closely relationship with lodging index, and it is the vital organ that transporting water and nutrients [7, 15], Culm is the main supporting system for photosynthetic organ and is also the pathway for transportation of water, nourishment and photosynthetic products, it play an important role in raising potential yield when breeding varieties [16, 20]. Domestic and overseas scholars focused on improving production target has made great achievements, and formed 3 kinds of theories to improve yield breeding, which is theoretical of yield components, theoretical of photosynthetic performance, theoretical of source - sink. Gonsiorkiewicz Rigon, etc. [6]who study ear length, ear diameter, cob diameter, grain row number, stem diameter, plant height, ear height, 100-grain weight, grain weight per ear and number of grains per ear, and found that grain weight per ear and ear length showed high correlation with grain yield. Pavlov, etc. [5] hold that number of leaves above the top ear has the strongest direct positive effect on grain yield, so as to height to tassel base and plant height. Huang Lu-Huan, etc. [21] research on removed tassel with leaf found that removed one leaf with tassel corn have the maximum biomass and single ear yield. Moreover, there are many researches on biomass, yield and economic coefficient [18]. However, there are few researches on top stem diameter and center stem diameter [17]. Meanwhile, using corn Jing Hua No. 8 as experimental materials in National Precision Agriculture Research Station, Xiao Tangshan, Beijing, explored the relationship between plant heights, stem height, base stem diameter, top stem diameter, center stem diameter and biomass, yield, economic coefficient of corn based on per corn plant. Defining the regular pattern and direct \& indirect effect of stem structure to yield potential, for the purpose of supplying reliable information and theoretical basis for breeding high potential yield variants, selecting agronomic traits of corn to meet the requirements. 


\section{Methods and materials}

\section{Study site}

The study was carried out in year 2015 at National Precision Agriculture Research Station, Xiao Tangshan, Beijing, located in $40^{\circ} 10^{\prime} 31^{\prime \prime}-40^{\circ} 11^{\prime} 18^{\prime \prime} \mathrm{N}, 116^{\circ} 26^{\prime} 10^{\prime \prime}-116^{\circ} 27^{\prime} 05^{\prime \prime} \mathrm{E}$, at $36 \mathrm{~m}$ average elevation. Using Jing Hua No. 8 as the test material, randomly selected group design and apply with three repeat $2 \mathrm{~m} * 6 \mathrm{~m}$ rectangle, 4 rows length at $6 \mathrm{~m}$, each row gap $0.66 \mathrm{~m}$, and column at $0.3 m$, as shown in Figure 1.

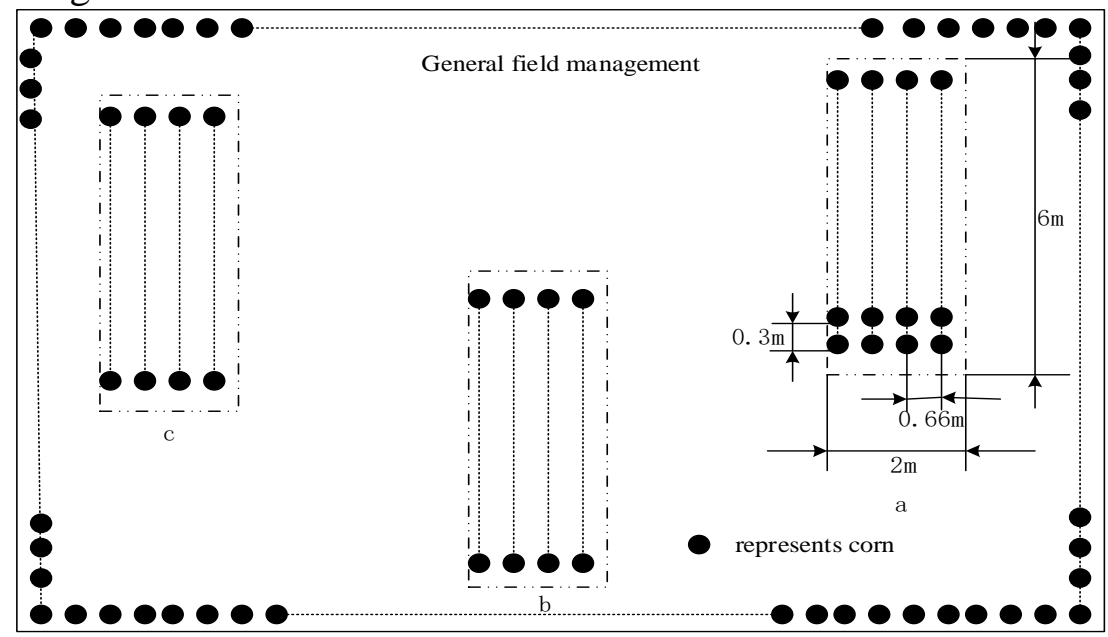

Fig 1 Experiment sample design

\section{Experimental design}

Measuring plant height, stem height, base stem diameter, top stem diameter, center stem diameter, biomass, and yield at small bell mouth stage, big bell mouth stage, tassel emerge stage. Plant height measurement before tasselling measure the height from the highest point of straightened leaves to ground, after tasselling measure the height from top of tassel to ground. Stem height measure from the top auricle to ground. Base stem diameter measurement method measure close ground nodes diameter at oblate. So as to top stem diameter measure node diameter at top auricle, and center stem diameter measure node diameter at half stem height.

The collected data was processed using spss19, matlab2010. Economic coefficient = yield / biomass, which represents the ratio of grain yield and the total aboveground weight, namely the potential grain yield. Economic coefficient affected photosynthetic products transportation.

\section{Methodology}

First of all, using grey relation analysis $[1,8,19]$ defines the degree of relationship between 5 agronomic traits (plant height, stem height, base stem diameter, top stem diameter, center stem diameter) and biomass, yield, economic coefficient. Secondly, adopting correlation analysis [10, 11, $13,22,23]$ further clarifies the relation is positive or negative. Finally, utilizing path analysis [2, 3, 4, $5,6,9,12,14]$ decomposes simple positive and negative correlation coefficient into direct and indirect effects. Thus certain which of the 5 agronomic traits had the biggest direct and indirect influence at positive and negative correlation relationship.

\section{Results and Analysis}

\section{Grey Relation Analysis of Maize Agronomic Traits \\ Grey Relational Analysis between Agronomic Traits and Biomass}

Analyzing plant height, stem height, base stem diameter, top stem diameter, center stem diameter by grey relation analysis. The correlation order was plant height $>$ stem height $>$ center stem diameter $>$ base stem diameter $>$ top stem diameter. In this analysis agronomic traits have a closely relationship with biomass, the correlation coefficients have little difference and almost above 0.75 . 


\section{Grey Relational Analysis between Agronomic Traits and Plant Yield}

Yield result shows the degree of sequence was similar with biomass, but the biggest factor of high yield was stem height. From the degree of changing sequence that stems height and plant height have slightly different in ranking order, but entire correlation coefficient lower than that of biomass.

\section{Grey Relational Analysis between Agronomic Traits and Economic Coefficient}

As can be seen from the result, top stem diameter had the maximum grey relation coefficient with economic coefficient 0.995, the top three factors was top stem diameter, base stem diameter, center stem diameter, but no big difference.

Overall, the result of grey relation analysis of plant biomass, yield, economic analysis, due to the interaction among agronomic traits, different references the sort is different. But it can be considered that Plant height and stem high have a significant impact on biomass and yield. Top stem diameter, center stem diameter, base stem diameter significantly influences on economic coefficient. Based on the principle of grey relation analysis grey coefficient representing the degree of relationship between agronomic traits and references, grey coefficient small means that the relationship is far. However, it does not reveal the effect is positive or negative, to further understand the impact of the action, we carried out correlation analysis.

\section{Correlation Analysis of Maize Agronomic Traits}

Correlation analysis result demonstrates that plant height and stem height have significant positively relationship $(\mathrm{P}<0.01)$, correlation between plant height and biomass is higher than stem height. But the correlation between stem high and yield, and stem high with economic factor is higher than the plant height. Plant height and stem height have a significant negative correlation with top stem diameter, Correlation coefficients are -0.74 and -0.83 , but have no obvious correlation with yield. Base stem diameter and yield are highly positively related, the correlation between base stem diameter and economic coefficient is 0.386 . The correlation coefficient of top stem diameter to economic coefficient, biomass, and yield is $0.734,-0.55$, and 0.381 .

\section{Path Analysis of Maize Agronomic Traits}

Firstly carried out data test, to made sure the reference (biomass, yield, economic coefficient) meets the path analysis, Shapiro-Wilk applicable to small sample test, as the number of samples test $\mathrm{n}=27$ belongs to small sample, Therefore, using Shapiro-Wilk Testing it. Shapiro-Wilk statistics were 0.961、0.96、0.932, and significant level were 0.395, 0.473, 0.111 all above 0.05 , the reference passed the test can do path analysis.

\section{Path analysis of biomass}

Obtained from path analysis, stem height, top stem diameter and base stem diameter direct effects were Pjg=0.414, Ptjc=-0.521, Psjc=0.349 (plant height: $\mathrm{zg}$, stem height: jg, base stem diameter: sjc, top stem diameter: tjc, center stem diameter: mjc). The significant result shows that Pjg, Ptjc, Psjc passed significant test, and the result was less than 0.05 . There is a significant difference between independent variable and dependent variable, which means the traits have significance statistical.

Table 1 decompose simple correlation coefficient of biomass

\begin{tabular}{llllcc}
\hline & \multicolumn{2}{c}{ direct effects } & \multicolumn{3}{c}{ indirect effects } \\
$\begin{array}{l}\text { Independent } \\
\text { variable }\end{array}$ & $\begin{array}{l}\text { Simple correlation } \\
\text { coefficient }\end{array}$ & $\begin{array}{l}\text { Path } \\
\text { coefficient }\end{array}$ & $\begin{array}{l}\text { stem } \\
\text { height }\end{array}$ & $\begin{array}{l}\text { top stem } \\
\text { diameter }\end{array}$ & $\begin{array}{l}\text { base stem } \\
\text { diameter }\end{array}$ \\
\hline $\begin{array}{l}\text { stem height } \\
\begin{array}{l}\text { top stem } \\
\text { diameter }\end{array}\end{array}$ & 0.607882 & 0.414 & - & 0.208208 & -0.0143 \\
$\begin{array}{l}\text { base stem } \\
\text { diameter }\end{array}$ & -0.56749 & -0.521 & -0.16559 & - & 0.118625 \\
\hline
\end{tabular}

According to path analysis significance of statistic, the maximum direct effect was top stem diameter, next is stem height, and base stem diameter was the minimum. By decomposed simple correlation coefficient on biomass found that top stem diameter through stem high is 0.208 , since the base stem diameter through stem height negative indirect effects to biomass is smaller making the simple coefficient of stem height to 0.607 . The negative indirect effect that stem height through top stem diameter on biomass almost the same to the positive indirect effect base stem diameter through 
top stem diameter on biomass, so the effect of top stem diameter biomass is -0.567 . The base stem diameter on biomass has the minimal simple correlation coefficient due most to the negative effect of top stem diameter through base stem diameter, which made base stem diameter be the minimal simple effect.

\section{Path analysis of Yield}

Path analysis of yield obtained that path coefficient base stem diameter to yield is 0.68 . Directly and indirect impact of agronomic traits to yield was small, that is to say other traits do not pass significance test.

\section{Path analysis of Economic Coefficient}

We can see from the table 2 that two agronomic traits have significance impact on economic coefficient, top stem diameter has the maximum direct effect, the center stem diameter followed by. Decomposed the simple correlation coefficient obtained that the top stem diameter through center stem diameter indirect and direct effect is 0.3478and 0.674. The results show that the top stem diameter direct and indirect positive effects on economic coefficient both the largest.

Table 2 Decompose simple correlation coefficient of economic coefficient

\begin{tabular}{lllcc}
\hline $\begin{array}{l}\text { Independent } \\
\text { variable }\end{array}$ & $\begin{array}{l}\text { dimple correlation } \\
\text { coefficient }\end{array}$ & $\begin{array}{l}\text { Path } \\
\text { coefficient }\end{array}$ & $\begin{array}{l}\text { top stem } \\
\text { diameter }\end{array}$ & $\begin{array}{c}\text { indirect effects } \\
\text { center stem } \\
\text { diameter }\end{array}$ \\
\hline $\begin{array}{l}\text { top stem diameter } \\
\begin{array}{l}\text { center stem } \\
\text { diameter }\end{array}\end{array}$ & 0.840901 & 0.673962298 & - & 0.166939 \\
\hline
\end{tabular}

In conclusion, the direct and indirect effects value of stem height, top stem diameter, and base stem diameter on biomass were $0.414,0.521,349,0.183,0.385$, and 0.133 . Only the base stem diameter into the yield path analysis, the direct effect value was 0.674 . Direct and indirect effect value of base stem diameter and center stem diameter on economic coefficient were 0.674, 0.324, 0.348, and 0.167. Not all stem structure of corn has a significant affected on biomass, yield, economic coefficient, figure 2 shows the significantly direct and indirect effects of stem structure. The size of the bar chart represents the direct effect and the length of fault bars indicate the indirect effect. Figure 2 shows that top stem diameter direct and indirect effect is obvious, which means that top stem diameter effect is the largest on biomass accumulation and plays an important role on conversion economic coefficient, and also affect filling rate of grain and duration.

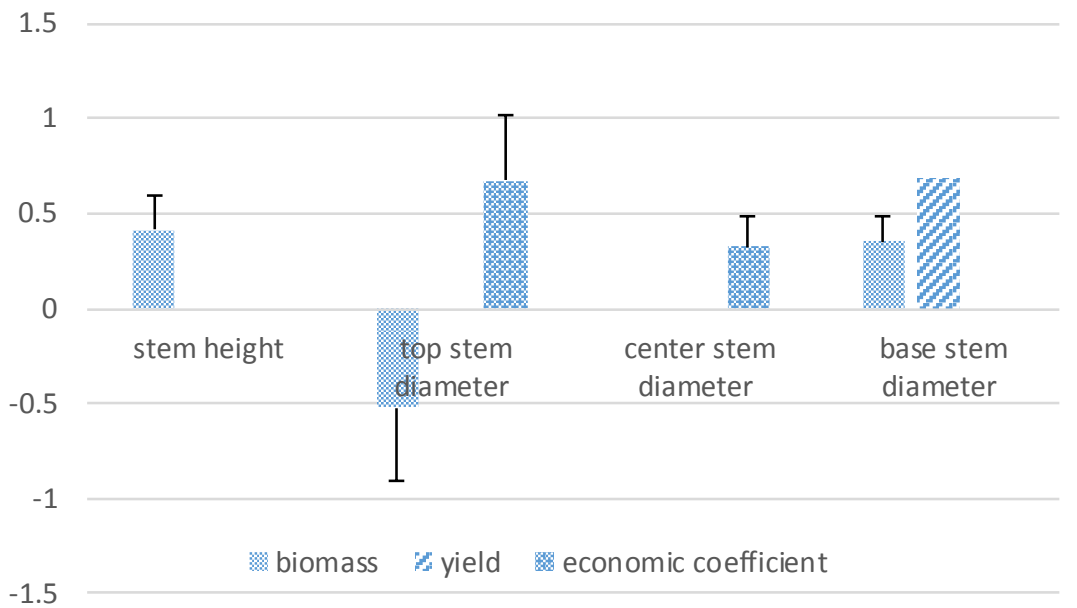

Figure 2 Impact of agronomic traits on yield potential

\section{Summary}

The grey relation coefficient revealed that plant height, stem height, base stem diameter, center stem diameter, and top stem diameter have significant effect on biomass, yield, and economic coefficient. Economic coefficient has the closest relationship with stem diameter, especially top stem diameter. 
The relationship was very close between biomass and plant height, stem height, the correlation coefficient was $0.777,0.732(\mathrm{P}<0.01)$, and the correlation coefficient of top stem diameter \& center stem diameter to biomass was $-0.55 \&-0.39$ (though significance test). The relation between yield and base stem diameter was 0.648 the highest, and top stem diameter \& center stem diameter was $0.381 \&$ 0.47(though significance test). Correlation coefficient $(\mathrm{P}<0.01)$ between economic coefficients and plant height, stem height, top stem diameter was $-0.61,-0.63,0.734$, center stem diameter, base stem diameter correlation coefficient was $0.566,0.386$ (though significance test).

Result of path analysis show that top stem diameter direct effect was -0.521 , and the indirect effect though stem height was 0.208 , which have the maximum effect on biomass. Base stem diameter shows high direct effect (0.68) on yield. Top stem diameter display direct effect (0.674) and indirect effect though (0.348) center stem diameter. And the effect of top stem diameter on base stem diameter and stem height big.

Overall, top stem diameter has the maximum direct and indirect influence on biomass, yield, and economic coefficient. Selecting the appropriate top stem diameter contribution to enhancing the potential yield of corn.

\section{Acknowledgment}

This work was supported by National Engineering Research Center for Information Technology in Agriculture (funding 2013AA102303). The authors wish to thank teacher Chang Hong, teacher Li Wei-Guo for their experimental guidance. And the author would like to thank the partner Wang Li-Zhi, Yue Ji-Bo, Dong Jin-Hui, Lu Guo-Zheng, Zhang Zhi-Hong, Yang Min, and Zhang Qi for carried out experiment.

\section{References}

[1] A. Kross, D.R. Lapen, H. McNairn, M. Sunohara, C. Champagne, and G. Wilkes, Satellite and in situ derived corn and soybean biomass and leaf area index: Response to controlled tile drainage under varying weather conditions. Agricultural Water Management 160 (2015) 118-131.

[2] A. Manickavelu, N. Nadarajan, S.K. Ganesh, R.P. Gnanamalar, and R.C. Babu, Drought tolerance in rice: morphological and molecular genetic consideration. PLANT GROWTH REGULATION 50 (2006) 121-138.

[3] A.S.D. Domenico, M.A. Danner, C. Busso, D. Christ, and S.R.M. Coelho, Análise de trilha da contaminação por aflatoxinas em grãos de milho armazenados. Pesquisa Agropecuária Brasileira 50 (2015) 441-449.

[4] F. Rodrigues, J.V. De Magalhaes, C.A. Brasil Pereira Pinto, F.D. Tardin, and R.E. Schaffert, CRITERIA FOR SELECTION OF SORGHUM LINES EFFICIENT AND RESPONSIVE TO APPLICATION OF PHOSPHORUS. REVISTA CAATINGA 27 (2014) 75-84.

[5] J. Pavlov, N. Delic, K. Markovic, M. Crevar, Z. Camdzija, and M. Stevanovic, PATH ANALYSIS FOR MORPHOLOGICAL TRAITS IN MAIZE (Zea mays L.). GENETIKA-BELGRADE 47 (2015) 295-301.

[6] J.P. Gonsiorkiewicz Rigon, C.A. Gonsiorkiewicz Rigon, and S. Capuani, QUANTITATIVE DESCRIPTORS AND THEIR DIRECT AND INDIRECT EFFECTS ON CORN YIELD. BIOSCIENCE JOURNAL 30 (2014) 356-362.

[7] K. Chartzoulakis, A. Patakas, G. Kofidis, A. Bosabalidis, and A. Nastou, Water stress affects leaf anatomy, gas exchange, water relations and growth of two avocado cultivars. Scientia Horticulturae 95 (2002) 39--50. 
[8] M. Blandino, M. Galeazzi, W. Savoia, and A. Reyneri, Timing of azoxystrobin + propiconazole application on maize to control northern corn leaf blight and maximize grain yield. Field Crops Research 139 (2012) 20-29.

[9] M. Toebe, and A. Cargnelutti Filho, Multicollinearity in path analysis of maize (Zea mays L.). Journal of Cereal Science 57 (2013) 453-462.

[10] M. Vaezi, and A. Kumar, Development of correlations for the flow of agricultural residues as slurries in pipes for Bio-refining. Biosystems Engineering 127 (2014) 144-158.

[11] P.P. Samuel, T. Chinnu, and M.K. Lakshmanan, Multi-parameter Analysis of Corn Using Near-infrared Reflectance Spectroscopy and Chemometrics. Materials Today: Proceedings 2 (2015) 949-953.

[12] S. Abirarni, C. Vanniarajan, S. Arurnugachamy, and D. Urna, Correlation and path coefficient analysis for morphological and biochemical traits in maize genotypes. PLANT ARCHIVES 7 (2007) 109-113.

[13] Y. Shao, J.B. Campbell, G.N. Taff, and B. Zheng, An analysis of cropland mask choice and ancillary data for annual corn yield forecasting using MODIS data. International Journal of Applied Earth Observation and Geoinformation 38 (2015) 78-87.

[14] Z. Sreckov, A. Nastasic, J. Bocanski, I. Djalovic, M. Vukosavljev, and B. Jockovic, CORRELATION AND PATH ANALYSIS OF GRAIN YIELD AND MORPHOLOGICAL TRAITS IN TEST-CROSS POPULATIONS OF MAIZE. PAKISTAN JOURNAL OF BOTANY 43 (2011) 1729-1731.

[15] Chen Yang, Chen Ya-jun, Zhou Yang, Yan Qing-wei, Li Xin, stem structure associated with Drought Resistance in different clover cultivar. ACTA AGRESTIA SINICA (2012) 686-691.

[16]Li Han-Bing, Bai Ke-Zhi, Kuang Ting-Yun, HUY u-xi, JIA Xu, LIN Jin-xing, structural characteristics of Thicker-culms in the high-yield wheat cultivars. Acta Botanica Sinica (2000) 1258-1262.

[17]Li Xiao-ming, Yang Zhong-fa, Zuo Ying-mei, Zhang Ting, Zhan Jian-xing, Dai Yu, Establishment of a Mathematical Model for Estimating Stem and Leaf Biomass of Cassava. CHINESE JOURNAL OF TROPICAL CROPS (2009) 440-444.

[18]Mo Yong-sheng, He long-fei, Huang Tianjin, Wei zheng, Nong you-ye, Rice Breeding Discussion of Thicker and Tougher. Chinese Agricultural Science Bulletin (2004) 82-86.

[19]Shen Zhong-bao, Wang Jian-li, Pan Duo-feng, Zhang Rui-bo, Li Dao-ming, Gao Chao, Di Guili, The Grey Relation Analysis of Agronomic Traits with Per Plant Yield of Soybean. Chinese Agricultural Science Bulletin (2012) 75-77.

[20] Yang Tai-xin, Wang zhi-wei, Chen Rui-xiu, Li rui-qi, Ma wen-xun, Analysis the different varieties maize Traits with yield. Journal of Agricultural Science (2011) 11-14.

[21]Huang Lu-Huan, Bai Gang -Shuan, Effects of De-tasseling with Top Leaf on Growth and Yield of Maize, Journal of Anhui Agri. Sci. (2015) 69-72.

[22]Zhang Jin-fang, Zhou Xian-qiong, Pu Xiao-bin, Li hao-jie, Jiang Liang-cai, Correlation analysis of the "Double low" hybrid rape yield Components with Yield. Agricultural Science \& Technology (2008) 82-83+117.

[23]Zhang Li, Dong Shu-ting, Liu Cun-hui, Wang Kong-jun, Zhang Ji-wang, Liu Peng, correlation analysis of the Maize Test Weight to yield and quality, Chinese Agricultural Science(2007) 405-411. 